\title{
Por um currículo multicultural
}

\author{
Carlos Odilon da Costa \\ Mestre em Educação pela FURB e Pesquisador do Educógitans/FURB \\ Rosana Soares \\ Mestre em Educação pela UDESC e Pesquisadora do Educógitans/FURB
}

\section{Resumo}

A pesquisa objetivou perceber como a construção curricular e as práticas pedagógicas nos Cursos de Artes-licenciaturas das Universidades Comunitárias de Santa Catarina possibilitam ou não momentos de promoção de igualdade para todos e todas. Após mapear as IES Comunitárias, a análise incidiu sobre os currículos trabalhados por seis Universidades: FURB, UNIVILLE, UNIPLAC, UNOESC, UNC, UNESC, no período de 2000 a 2007. Nos planos de ensino dos professores e na bibliografia recomendada, constatamos a presença de autores que abordam o multiculturalismo. Resta saber como os graduandos se posicionaram frente às teorias apresentadas e como essas teorias estão inseridas em suas práticas docentes.

Palavras-chave: Multiculturalismo; Arte-Educação; Mapeamento.

\begin{abstract}
The research aimed to perceive how the curriculum construction and pedagogic practices in Art Courses - Licentiate degree - of the Community Universities of Santa Catarina allow or not moments of equality promotion to all. After mapping Community IES, happened the analysis of the curricula performed by six universities: FURB, UNIVILLE, UNIPLAC, UNOESC, UNC, UNESC, at the period from 2000 to 2007. In the the teaching plans and in the recommended bibliography, we accused the presence of authors who approached multiculturalism. It lacks to know how graduating students position themselves towards the presented theories and how these theories are inserted in their teaching practices.
\end{abstract}

Keywords: Multiculturalism; Art-Education; Mapping. 
$\mathrm{P}$ ara viver democraticamente em uma sociedade plural é preciso respeitar e valorizar a diversidade étnica e cultural que a constitui. A multiplicidade de raízes da nossa formação cultural não pode ser desconsiderada sob pena de se priorizar apenas a visão hegemônica e unilateral do mundo. Nesse sentido resgatar, valorizar e respeitar a cultura do outro se torna, em nosso mundo globalizado e conflituoso, formas de se proporcionar nos ambientes escolares, relações de acolhimento e amorosidade para com o outro e outra. Entender e valorizar o outro e outra diferente, em nosso caso o ser indígena e o Afro-descendente, acarreta conhecer a abordagem cultural em que vivemos. O conhecimento de nossas raízes étnicas e culturais é fundamental para a afirmação da nossa identidade brasileira multiétnica e pluricultural. Contudo, em nossas universidades, espaços privilegiados de construções e transmissão do saber e da cultura, pouco se falou e pouco se fala sobre o respeito à cultura e etnia do outro.

Essa omissão histórica infelizmente resultou em uma sociedade brasileira conhecida por suas atitudes de discriminação e preconceito ao indígena e também ao afro-descendente. Nossas universidades que estão inseridas nesta sociedade também não escapam desses movimentos e ações que aumentam a divisão entre os seres que compõem nosso país e constroem as desigualdades sociais. As questões referentes às desigualdades sociais podem estar vinculadas à forma como as pessoas e os povos organizam a partilha dos bens disponíveis e produzidos. Stuart Hall (1998, p. 8) neste sentido cita em suas obras seu reconhecimento de que as sociedades capitalistas industriais se apresentam como lugares de divisões desiguais, tanto no que se referem aos recursos quanto ao direito/merecimento em função da etnia, sexo, idade, divisões de classes, dentre outras, estabelecidas pela cultura, pela história de cada povo e pela tradição. Stuart Hall (1998, p. 21) afirma que a cultura é um dos locus onde estabelecemos as divisões, mas também é nela que constituimos o meio em que elas podem ser contestadas. É na cultura que se dá a luta pela significação dos valores, tanto de dominação quanto de resistência e 
libertação. É na cultura que os grupos subordinados tentam resistir à imposição de significados que sustentam os interesses dos grupos dominantes. A história da cultura do povo brasileiro é farta de exemplos em que os poderosos usaram sua cultura e se apropriaram da cultura da população, adaptando-a para se constituir em instrumento de exploração, opressão, subordinação e acomodação dos menos favorecidos ou com pouca participação no mecanismo social existente na sociedade.

A literatura oferece um vasto leque de informações a respeito do assunto colonização e exploração dos povos oprimidos e subjugados, dos quais destacamos o teólogo Leonardo Boff (1992, p. 9) ao dizer que:

A conquista e colonização das Américas constituíram um ato em si de grandíssima violência. Implicou que uma nação com sua cultura, memória, religião e história, se submetem a outra, perdendo seu caráter de sujeito histórico-cultural.

E acrescenta ainda que toda colonização e conquista desestrutura a cultura submetida. Obrigando as pessoas e os grupos a internalizar a figura do colonizador e reprimir os legítimos reclames de libertação e justiça. Todos e todas oprimidos(as) passam por um terrível dilema, ou se submetem ao colonizador, e então atraiçoam seus irmãos e irmãs, e assim vivem como sujeitos subalternos e dependentes, ou então resistem e se rebelam e são perseguidos, condenados a viver na clandestinidade, presos, torturados ou mortos. Outros para sobreviver se submetem a viver sob disfarces, evitando sua própria identidade. Esta referência traz para a memória a lembrança do testemunho de inúmeras pessoas, de grupos sociais organizados a partir dos colonos europeus, que se instalaram no Estado de Santa Catarina, que tinham parentesco próximo com os indígenas, mas que negavam este vínculo, não permitindo sequer tocar no assunto. A ascendência étnica se caracteriza desta forma como um importante aspecto que determina o grau ou o nível de aceitação social a que as pessoas estão sujeitas.

Um dos maiores responsáveis para que o processo de reprodução 
social apoiado na exploração dos diversos povos indígenas brasileiros e dos afro-descendentes foi o modelo de educação conhecido como educação escolar européia, que se formulou e executou, tendo como referência o sistema formal, que tinha como base de sustentação a escola e o letramento das elites, o que caracterizou uma educação escolar centrada no modelo ocidental europeu, que infelizmente reproduziu uma sociedade desigual, apoiada no eurocentrismo e no arianismo. Esse é o retrato infeliz de nossa educação. Um espaço onde pouco falamos sobre a identidade do ser indígena e afro-descendente. A cultura desses diversos povos passou, de geração em geração, por um anonimato nos currículos escolares. Nesse sentido a professora Conceição (1999, p. 90-91) nos alerta que:

O silêncio historiográfico sobre o negro, que aparece tanto no currículo oficial, enquanto definidor do conteúdo programático, quanto na própria concepção historiográfica ensinada no nível fundamental e médio, tem levado nestes anos de docência no magistério de História, a não apenas constatar o déficit da História Nacional para com o povo negro, mas acima de tudo vislumbrar alternativas que serão úteis como elementos de justificativas para imprescindíveis mudanças e questionamentos aquilo que temos enquanto proposta de ensino de História imposta e quase que inatacável sobre os que não participam do registro oficial da historiografia brasileira; os que ficaram à margem dos códigos da erudição neste país, a exemplo dos negros, índios, etc.

A reflexão em torno da problemática levantada indica possíveis caminhos, que seriam os de olhar mais de perto as experiências que os acadêmicos vivenciam. A universidade precisa aprender para propor às escolas situações de aprendizagens que promovam a autonomia e protagonismo de diferentes etnias. Discussões acerca das relações "raciais", do preconceito racial e suas manifestações na sociedade brasileira e em particular na escola, bem como a valorização e compreensão da importância das diversas culturas dos diversos povos indígenas e dos diversos povos originários da África que se estabeleceram no Brasil e com sua enorme contribuição na constituição cultural, social, econômica, geográfica, histórica, religiosa, científica e educacional para o Brasil, precisa ser feita, para então podermos refletir sobre o quê e por quê deve ser escolhido como 
conteúdo para compor um currículo escolar que privilegie um deslocamento do olhar sobre os diversos povos indígenas e afro-descendentes na nossa história, cultura e educação. Um dos princípios que devem orientar os temas, os projetos e as atividades pedagógicas em relação à questão da matriz indígena e afro-descendente na escola é a desconstrução do preconceito e a reafirmação de uma auto-estima positiva das populações indígenas e o ser negro. Ensinar a aprender sobre e na diversidade, propor situações de aprendizagem que sejam desafiadoras e que tragam novos conhecimentos são cuidados que devemos ter quando o que estudamos vem carregado de imagens e crenças baseadas no preconceito e na discriminação. A cultura brasileira está repleta da presença indígena e afro-descendente, muitas vezes não reconhecida em nossos currículos e atividades, que precisa ter visibilidade junto aos alunos e alunas.

Cabe enfatizar também que o princípio estruturador das ações e projetos pedagógicos é a igualdade como base. A igualdade pressupõe semelhanças e diferenças, mas não contempla a inferioridade, que é a marca do preconceito e da discriminação racial. Dessa perspectiva não existem raças humanas diferenciadas que devam ser dispostas em uma escala de inferior a superior, é essa visão que devemos ultrapassar nos programas curriculares, nas pesquisas e escolhas de conteúdos. As diferenças raciais, culturais ou outras só podem ser contempladas quando a igualdade humana é tomada como base, caso contrário o que surge é a discriminação. Nesse momento é preciso ampliar nosso repertório de informações sobre a participação indígena e afro-descendente na cultura e história nacional para alargar o sentido dessa igualdade, não somente pela fala, mas pela democratização das imagens e conteúdos explorados em sala nas diversas atividades sugeridas e feitas. Tarefas que exigirão dos futuros professores um esforço coletivo e participativo. O grande desafio para qualquer professor ou professora é manter na sua prática cotidiana os princípios éticos de respeito à vida e às diversas culturas e etnias existentes em nosso planeta, que ele próprio acredita. Se o preconceito racial reside na 
subjetividade humana e é apreendido socialmente, e confirmado pelas diversas experiências das pessoas, temos dois cuidados importantes a serem tomados nessas relações. Um deles está no plano de atitudes que também ensinam e formam indivíduos, e o outro no das escolhas dos conteúdos ou das abordagens a ensiná-los. Nesse sentido, diversas devem ser as tentativas de arranjos curriculares, desde a inclusão dos novos conteúdos até a pesquisa de novas abordagens para conteúdos a antigos, possibilitando concepções e perspectivas que privilegiem o modo de ver e compreender o mundo das populações indígenas e os afro-descendentes. Nas palavras de Mclaren (2000), essa compreensão pode ser experimentada por aquilo que ele denomina de Multiculturalismo Crítico e de Resistência, ou seja, o Multiculturalismo sem uma agenda política de mudança pode apenas ser outra forma de acomodação a uma ordem social maior, em suas palavras seria (2000, p. 123-124),

O multiculturalismo de Resistência não compreende a diversidade como uma meta, mas argumenta que a diversidade deve ser afirmada dentro de uma política de crítica e compromisso com a justiça social. Ele tem de estar atento à noção de diferença. Diferença é sempre um produto da história, cultura, poder e ideologia. A diferença ocorre entre dois grupos e entre muitos grupos e deve ser compreendida em termos de especificidade de sua produção. O multiculturalismo crítico questiona a construção da diferença e identidade em relação a uma política radical. Ele se posiciona contra o romance neo-imperial, sustentado em uma experiência compartilhada ou comum da América que está associada às tendências conservadoras e liberais do multiculturalismo.

Portanto, ao considerar o tema currículo de artes e relações étnicoraciais, como portador de relações que envolvem conteúdos complexos, precisamos de persistência se optamos pela linha de transformação, que é um dos atributos da universidade e da escola. Deslocar o modo de ver eurocêntrico, que está na base dos currículos, só tornará mais rico e profundo o conhecimento que será visto por diferentes pontos de vistas. Sem dúvida esse é um longo caminho que precisamos percorrer, pois não é nada fácil incluir novas concepções de conhecimentos já adquiridas, principalmente aquela que de certa maneira influencia o modo de ser e agir 
no mundo, um mundo pautado na ética de respeito à vida e às diversas culturas e etnias existentes.

Ao voltarmos nossa atenção para o início da educação no Brasil e para as concepções teóricas que conduziram este campo de estudo, notamos um começo quase promissor. É na pessoa do Padre Manoel da Nóbrega que a noção de uma educação para a emancipação ganha destaque. Apesar de alguns equívocos aceitos na época (segregação do negro e da mulher), podemos notar uma preocupação por parte deste educador em construir uma sociedade harmoniosa e de interesses múltiplos.

A educação jesuítica, nos chamados "tempos heróicos" (primeiros 21 anos 1549 - 1570), comandados pelo Padre Manuel da Nóbrega, era organizada em recolhimento onde eram educados os mamelucos, os órfãos, os indígenas (especialmente os filhos dos caciques) e os filhos dos colonos brancos dos povoados. Nóbrega entrevia a necessidade de "alicerçar nessa unidade espiritual e escolar a futura unidade política da nação" e por isso os recolhimentos funcionavam "como agências de democratização, aproximando as raças e os filhos provenientes de diversas condições de vida, irmanando-os no trabalho, pela igualdade de tratamento e pelo convívio diário no colégio, na capela, nos pátios de recreação (Zotti, 2004, segundo Mattos, p. 16).

Para uma nação jovem a ser colonizada e dominada, as idéias igualitárias e democráticas de Nóbrega eram inviáveis para um desenvolvimento da colônia planejada, e logo esses ideais educacionais foram substituídos, ainda pela catequese jesuítica, que rapidamente se volta para a educação do homem branco da elite, segregando índios e pobres. O cenário educacional brasileiro caminha no ritmo da educação estrangeira: discriminatória, elitista, desigual, controladora, dominadora.

As normas dos colégios jesuítas eram padronizadas e foram oficialmente publicadas em 1599 no Ratio Studiorum. Este plano de estudos levou 59 anos para ser elaborado, o que possibilitou uma grande experiência e larga discussão ate ser publicada. Não foi um plano de um homem ou um grupo fechado, mas de uma experiência comum (Franca, 1986). Podemos dizer que no Ratio Studiorum "tudo estava previsto, regulamentado e discutido, desde a posição das mãos, ate o modo de levantar os olhos" (Ponce, 1990, p. 122), constituindo-se numa coleção de regras e prescrições praticas e detalhadas. 
Ou seja, um currículo que ia muito alem das disciplinas ou conteúdos escolares (Zotti, 2004 p. 20).

A escola e o currículo eram ferramentas indispensáveis na modelagem do corpo e da mente dos sujeitos, herança herdada até hoje. Toda essa preocupação de controle com o objetivo de fortalecer a economia e o desenvolvimento da colônia que muito prometia, mas que necessitava de um trabalho árduo de desenvolvimento. Os jesuítas e sua fórmula de educação permanecem no Brasil por 210 anos. Tempo suficiente para aniquilar qualquer idéia democrática e igualitária do início de sua colonização. O Estado assume os rumos da educação a partir de então, com a Reforma Pombalina liderada por Sebastião José de Carvalho e Mello, conhecido como Marquês de Pombal, ministro de D. José I, que objetiva revigorar a educação e fortalecer economicamente Portugal, buscando a educação dos nobres. Neste momento, todos os interesses estavam voltados para Portugal, e a educação brasileira fica suspensa, sem os jesuítas, no entanto, também sem nenhuma reforma educacional.

A Reforma pombalina, no Brasil, não foi imediata. Somente em 1772, 13 anos após a expulsão dos jesuítas e do alvará de 28 de junho de 1759 - que instituiu as aulas de gramática latina, de grego e de retórica e criou o cargo de "diretor de estudos" para orientar e fiscalizar o ensino além de selecionar, através de exames, os professores - é que foram estabelecidas as aulas de primeiras letras, de gramática, de latim e de grego no Rio de Janeiro e nas principais cidades das capitanias (Zotti, 2004, segundo Azevedo, 1976; Ribeiro, 1998).

Novamente a educação tinha como foco os nobres, a massa não deveria ser considerada importante. A colônia deveria cumprir com sua função agrícola, era preciso força na mão de obra.

O currículo, de modo geral no período colonial, cumpriu seu objetivo à medida que, construído no modelo europeu, traduzia a concepção de mundo do colonizador, formando o dirigente para a manutenção da sociedade de acordo com seus interesses, especialmente os econômicos. Portando, estender o ensino à maioria da população nunca interessou a aristocracia agrária, que via seu papel restrito a educação da elite (Zotti, 2004 p. 32). 
Notamos desde a colonização e as idéias de Nóbrega que, quando o interesse de desenvolvimento econômico sobrepõe o desenvolvimento humano como condição justa e democrática, as reformas apenas utilizam novo discurso, mas mantêm a raiz doentia de exploração de uns sobre muitos. É assim no Brasil Império, onde o Decreto Imperial de15 de outubro de 1827 rege a educação e elege o que deve ser ensinado e a quem

Os professores ensinarão a ler, escrever, as quatro operações de aritmética, prática de quebrados, decimais e proporções, as noções mais gerais de geometria prática, a gramática da língua nacional, os princípios de moral cristã e de doutrina da religião católica e apostólica romana, proporcionadas a compreensão dos meninos; preferindo para o ensino da leitura a Constituição do Império e História do Brasil (Zotti, 2004, p. 53-54).

O objetivo das diretrizes educacionais era levar os nobres à formação superior, por isso alguns saberes eram considerados fundamentais. Surge no período da Primeira República a inserção de saberes relacionada aos Estudos Científicos e de Humanidades, sendo que esta área de conhecimento (humanas) conquista uma brecha na educação, influenciada pelas idéias iluministas que dominavam a Europa. "Durante o período de 1930 a 1964, três grandes reformas acarretaram mudanças na organização curricular do ensino secundário" (Zotti, 2004, p. 103), sendo elas: Reforma Francisco de Campos, 1931; A Reforma Capanema, 1942 e a Lei de Diretrizes e Bases da Educação Nacional - Lei n 4.024/61, sendo que vale ressaltarmos a relevância do ensino da educação artística na Reforma Capanema.

A matriz curricular apresentou um equilíbrio no que diz respeito ao ensino das humanidades e das ciências. Em sete anos de escolarização, as humanidades estavam presentes com $35,4 \%$, as ciências com $30,5 \%$, os estudos sociais com 20,7\% e a educação artística com 13,4\% (Zotti, 2004, p. 137).

A arte como formadora da população se inicia de forma tímida e com muitos equívocos, de forma ainda técnica. Mas é uma conquista que deve ser considerada como um passo a mais de um caminho que também 
precisa ser construído. A educação no Brasil, com suas reformas, suas leis, ainda está diretamente voltada para o desenvolvimento econômico, uma prioridade que se inicia com sua colonização. No entanto, neste entremeio, existem sujeitos que de forma nem sempre esperada atuam na sociedade. As teorias que permeiam o meio educacional, pouco podem fazer para a mudança das leis que regem a educação talvez influenciarem na próxima revisão da lei as mudanças aspiradas por aqueles que acreditam na educação como emancipação. Mas pensar sobre o cenário educacional que hoje se apresenta é fundamental para escrevermos nosso tempo na educação. Um tempo que propõe reparos, pretende promover a igualdade social e racial, tendo os equívocos do passado como foco propulsor para as mudanças necessárias. Talvez a educação através da arte ainda necessite, por parte de alguns educadores, esse olhar global na formação do sujeito. Certamente, o caráter técnico e funcionalista da inserção da arte na escola confere ainda à disciplina determinados conceitos incorretos, como, por exemplo, o caráter técnico-prático, reduzindo este como sendo o objetivo maior. Mas a educação através da arte almeja e possibilita muito mais.

Mesmo entendido como importante na formação humana, o ensino da arte perde em conteúdo quando discutem acirradamente quais seriam as metodologias para seu ensino, ou seja, a busca de práticas e técnicas que possam oferecer ao aluno saberes considerados necessários.

Temos cada vez mais corrido atrás de novidades pedagógicas em termos de técnicas: dinâmica de grupo, áudios-visuais, avaliações objetivas, etc., sem, no entanto, preocuparmos-nos com os fins da educação. Sem discutirmos o que, como e porque ensinar. Substituímos a opinião pessoal por um palavrório oco e inautêntico, que tomamos dos livros-textos e o repetimos infinitamente, maçantemente (Silva, 2007, p. 83)

Essa concentração em como fazer deixar de lado um envolvimento maior da arte na educação, que deveria buscar um entendimento de por que fazer? Toda essa aflição metodológica e didática reafirma a necessidade de se justificar a presença da arte no currículo. 
Pois, atualmente, a discussão em torno de uma arte-educação contemporânea enfatiza a interculturalidade, que preserva a identidade cultural e toma o devido cuidado para evitar uma possível hegemonia cultural. Outras questões vão aparecer como posturas do ensino da arte, como o multiculturalismo e a teoria queer ${ }^{1}$. Recentemente assuntos como direitos humanos, ecologia, fome, racismo, política, religião, medicina e inúmeras questões que envolvem a internet são discussões que precisam de uma reflexão, e todas elas perpassam a educação. Interessa saber de que forma estas questões são discutidas no currículo, se é que são. Em meio à diversidade, tanto o indivíduo como o coletivo são importantes no desenvolvimento dos saberes, e a dinâmica dessa relação entre gênero, raça, etnia, classe deve ser observada ao propormos um currículo de artes. Sendo assim, uma pergunta se fortalece ainda mais: o que significa neste cenário contemporâneo ensinar e aprender? Quais deveriam ser os componentes de um currículo comprometido com a vida real que se apresenta diariamente? Quais são os saberes necessários para o processo formativo, que objetiva a intervenção social e melhoria da vida humana? Sendo assim, ao nos debruçarmos sobre o currículo para seu estudo, inúmeras questões devem ser consideradas, entre elas o significado do conhecimento e aprendizagem, a complexidade do ato de educar e compreender a escola como um espaço de ensino e aprendizagem, porém não o único. $\mathrm{O}$ universo de saberes que acompanha o educando deve ser reconhecido, bem como as diferenças culturais não podem ser esquecidas na hora de pensarmos no currículo. $\mathrm{O}$ currículo não pode ser aceito como uma regra ou paradigma; o currículo hoje é constantemente pensado, problematizado, revisto.

Neste sentido esta pesquisa caminhou para perceber como a construção curricular e as práticas pedagógicas nos Cursos de Artes -

\footnotetext{
${ }^{1}$ Queer, do inglês: estranho, esquisito, efeminado, bicha - inverte o sentido negativo do termo e contribui tanto para afirmar os direitos das diferentes opções sexuais como para minar, de dentro, um pensamento que encerra o outro em uma etiqueta, pretendendo-se a si mesmo invisível a teoria queer questiona os binômios de identidade, o caráter unitário da subjetividade e, principalmente, as idéias liberais referentes à autonomia do indivíduo e o conceito de comunidade com base no princípio da uniformidade
} 
licenciaturas das Universidades Comunitárias de Santa Catarina possibilitam ou não momentos de intensa promoção de igualdade e justiça para todos e todas, em especial aqueles e aquelas que, no decorrer de nosso processo histórico, foram vítimas de grandes opressões e exclusões. Entender e descrever a fundamentação teórica dos currículos escolares referentes à diversidade cultural foi o objetivo maior. Também possibilitar o entendimento de como se apresenta a construção curricular baseada na abordagem étnica do ser indígena e do afro-descendente das IES comunitárias de Santa Catarina. A Sociedade Catarinense também reproduziu a exploração, opressão e discriminação para com os povos indígenas e os afro-descendentes, tendo como modelo as idéias oriundas dos grandes centros brasileiros e porque não afirmar de todo o território nacional, onde os indígenas e afro-descendentes eram tratados como animais ou simplesmente mercadorias. Esse fato proporcionou que, na região de Santa Catarina, os indígenas e os afro-descendentes fossem retratados e hostilizados como seres inferiores e repugnantes, até mesmo o preconceito de serem malandros, arruaceiros, entre outros termos pejorativos. Isto levou a termos uma relação conflituosa entre indígenas e afro-descendentes versus descendentes de europeus. As Universidades da região que estão inseridas nesta sociedade também não escapam desses movimentos e ações que aumentam a divisão e entre os seres que compõem nosso país. Muitas vezes a própria instituição, que deveria promover por meio de um currículo que privilegiasse formas de relações pacíficas entre os indivíduos de diversas etnias, acaba por não dar a atenção devida ao assunto, neste sentido a pesquisa caminhou na direção de constatar quais teorias da diversidade cultural, através dos autores referenciados na bibliografia das ementas dos professores, estão presentes nos currículos dos cursos de artes plásticas - licenciatura, das IES comunitárias de Santa Catarina.

A pesquisa foi desenvolvida a partir de observações e análises dos currículos trabalhados por seis Universidades Comunitárias de Catarina no 
curso de artes - licenciatura - no período de 2000 a 2007. Este recorte no tempo é orientado devido às modificações curriculares por qual passaram as Universidades pesquisadas: FURB, UNIVILLE, UNIPLAC, UNOESC, UNC, UNESC. Em análise feita nos planos de ensino dos professores, na bibliografia recomendada, constatamos a presença de autores que problematizam o multiculturalismo, como: Peter Mclaren, Stuart Hall, Raquel Mason, Fernando Hernández e Ana Mae Barbosa.

Sendo os autores propulsores de idéias mestras de pensamento que resultam em ação, resta saber como os graduandos absorveram e se posicionaram frente às teorias apresentadas e como essas teorias estão inseridas em suas práticas docentes?

\section{Referências}

BOFF, L.. América Latina da conquista a nova evangelização. São Paulo: Ática, 1992.

CONCEIÇÃO, M. T. Os Negros e a Escola Brasileira. Florianópolis: Atilende, 1999.

HALL, S. A Identidade Cultural na pós-modernidade. $7^{\mathrm{a}}$ ed. Rio de Janeiro: DPeA, 1998.

RIBEIRO, D. As Américas e a Civilização. Petrópolis: Vozes, 1983.

SILVA, Tomaz Tadeu. Documentos de Identidade: uma introdução às teorias do curriculo. Belo Horizonte: Autêntica, 2007.

ZOTTI, S.A. Sociedade, Educação e Currículo no Brasil: dos Jesuitas aos anos de 1980. Campinas, SP: Autores Associados; Brasília, DF: Editora Plano, 2004. 